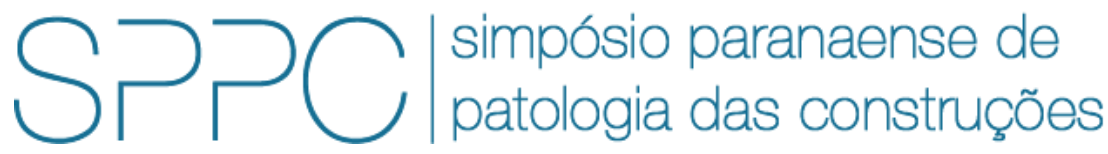

ISSN 2526-7248 artigo 2SPPC1033, pp. 392-405, 2017

\title{
Avaliação comparativa do comportamento mecânico de concretos leves com ar incorporado
}

\author{
MARIZ, Jairo Colaço ${ }^{1}$, MONTEIRO, Eliana Cristina Barreto ${ }^{2}$ e COSTA E SILVA, Angelo Just ${ }^{3}$ \\ ${ }^{1}$ Engenheiro Civil, Tecomat Engenharia, jairo.mariz@gmail.com \\ 2 Profa. Dra., Universidade de Pernambuco, eliane@poli.br \\ 3 Prof. Dr., Universidade de Pernambuco, angelo@tecomat.com.br
}

\begin{abstract}
Resumo: O conhecimento dos materiais de construção, seus comportamentos e suas propriedades é de fundamental importância para a definição de suas aplicabilidades e no entendimento da melhor solução a ser adotada para cada necessidade no campo da construção civil. No caso específico dos concretos, é importante falar sobre seus componentes, suas propriedades e seu comportamento diante de diversas situações. Este projeto apresenta o resultado dos estudos de dosagem para a produção de concretos leves com uso de aditivo incorporador de ar, tendo em vista seu crescente uso em aplicações como paredes de edificações habitacionais. Importantes aspectos a serem considerados com a incorporação de ar foram as mudanças das características mecânicas dos concretos em estudo tais quais absorção, absorção capilar, resistência mecânica, dentre outras, quando com uso do aditivo incorporador. Observou-se que a incorporação de ar, acarretou na redução de massa específica dos concretos e, além disso, promoveu diminuição das resistências à compressão e o aumento da absorção e absorção capilar, o que possui relação com os vazios presentes nos mesmos e que pode vir a influenciar no que diz respeito à durabilidade dos elementos de concreto. Observa-se que, a depender da classe de densidade do concreto adotado, é importante avaliar a permeabilidade do mesmo como fator de se adotar medidas necessárias para reduzir a possibilidade de efeito deletérios tais quais o fenômeno da carbonatação e ataque por cloretos a depender da agressividade da região de influência aonde estes concretos estejam inseridos.
\end{abstract}

Palavras-chave:Concreto leve; ar incorporado; parede de concreto; resistência à compressão; capilaridade; absorção.

Abstract: The Knowledge about construction materials, their behavior and properties has a fundamental role in the definition of the applicability of construction materials and the understanding of the best solution to be adopted for each need in the field of construction. In the specific case of concrete, it is important to discuss about its components, properties and behavior in many situations. This work presents the results of concrete mix design studies for producing lightweight concrete with air entraining admixture agents. The use of this admixture has increased lately (in Brazil), such as in applications of walls of buildings housing. An important issue to be considered using the air entraining admixture is the change of some mechanical characteristics, such as, absorption, capillary absorption, and mechanical strength. It was noted that the incorporation of air caused the reduction of specific mass of concrete and, in addition, caused a decrease of mechanical strength and increased capillary absorption and absorption, related with air entrainment present therein which may influence in the durability of some structures. It is important to evaluate the permeability of these concretes, which depends of its density, to prevent possible causes of pathologies to know carbonation and chloride attacks which may occur if those concretes were in such atmospheres.

Keywords: lightweight concrete; air entraining; concrete wall; concrete strength; capillarity; absorption. 


\section{Introdução}

O concreto de cimento Portland é o material estrutural mais importante da construção civil na atualidade. Conforme descrito por Helene [1], mesmo sendo o mais recente dos materiais de construção de estruturas, pode ser considerado como uma das descobertas mais interessantes da história do desenvolvimento da humanidade e sua qualidade de vida.

O uso de concreto na produção de unidades habitacionais através do sistema de paredes de concreto moldadas in loco apresentou grande crescimento nos últimos anos. Em evidência se apresentam os sistemas de paredes de concreto moldadas in loco. Estes sistemas são utilizados em obras no país há cerca de 30 anos segundo Corsini [2], dividem-se basicamente em dois tipos, a depender do concreto adotado: parede de concreto com densidade normal e paredes de concreto leve. Para a regulamentação do sistema de paredes de concreto convencional, foi publicada em 2012 uma norma respectiva, a NBR 16055 [3]. Para sistemas de paredes com concreto leve espumoso existem normas que datam de 1992. Estas normas, contudo, estão em revisão atualmente. O sistema de concreto leve não estrutural adotado por algumas empresas pode vir a ser interessante desde que se conheçam suas limitações e seu comportamento.

Este projeto avaliou, por meio de um desenvolvimento experimental, concretos com ar incorporado e algumas de suas propriedades mecânicas de forma comparativa. Para tanto foram produzidos concretos com distintas densidades obtidas através do uso de aditivo incorporador de ar associado às dosagens pré-determinadas em estudo.

A definição dos traços de concreto para cada grupo, com e sem utilização de aditivo incorporador de ar foi acompanhada também da determinação das relações água/cimento, a/c, utilizadas para cada relação cimento/agregados, c:m considerada, além dos ensaios de resistência à compressão dos concretos para cada massa específica e relação água/cimento seguiu-se no estudo, da determinação da absorção, índice de vazios e massa específica dos concretos em seu estado seco, da determinação da massa específica, teor de vazios dos concretos em estado fresco e da avaliação da absorção de água por capilaridade,e ainda da avaliação da profundidade de carbonatação das amostras de cada grupo de concreto do estudo.

\subsection{Concretos leves}

Conforme apresenta Rossignolo [4], os concretos leves caracterizam-se pela redução da massa específica em relação aos concretos convencionais, conseqüência da substituição de parte dos materiais sólidos por ar. Podem ser classificados em concreto com agregados leves, concreto celular e concreto sem finos. Segundo a NBR 8953 [5], os concretos são classificados pela massa específica conforme a tabela a seguir. 
MARIZ, J. C.; MONTEIRO, E. C. B.;COSTA E SILVA, A. J., AVALIAÇÃO COMPARATIVA DO COMPORTAMENTO MECÂNICO DE CONCRETOS LEVES COM AR INCORPORADO. $2^{\circ}$ Simpósio Paranaense de Patologia das Construções ( $2^{\circ}$ SPPC), artigo 2SPPC1033, pp. 392-405, 2017. DOI: 10.4322/2SPPC.2017.033

Tabela 1: Classificação quanto à massa específica. Fonte:NBR 8953

\begin{tabular}{|c|c|}
\hline Nomenclatura & $\begin{array}{c}\text { Massa específica seca } \\
\left(\mathbf{K g} / \mathbf{m}^{3}\right)\end{array}$ \\
\hline Concreto leve $(\mathrm{CL})$ & $<2000$ \\
\hline Concreto normal (C) & 2000 a 2800 \\
\hline Concreto pesado ou denso (CD) & $>2800$ \\
\hline
\end{tabular}

A análise das massas específicas obtidas para grupos de concreto permite uma correlação com a inclusão de vazios nos mesmos. A relação entre o conteúdo de ar aprisionado intensionalmente e a massa específica é bastante direta; um aumento no volume do ar promove uma redução nos valores de massa específica, mantendose a mesma relação de materiais. Desta forma, a diminuição das massas específicas dos concretos é obtida através da inclusão destes vazios em seu interior.

O grupo de concretos leves, ainda assim é amplo e não caberia simplesmente classificá-los pelas suas massas específicas, tão somente. Outras características também são levadas em consideração. A forma como são produzidos, isto é, que materiais e processos são considerados na sua elaboração, a resistência mecânica, a trabalhabilidade, a retração e fluência, entre outras.

\subsection{Aditivo incorporador de ar}

Os aditivos incorporadores de ar apresentam a função de produzir um grande número de bolhas de ar, estáveis, distribuídas uniformemente dentro do concreto.

Segundo Mehta [6], os aditivos incorporadores de ar são produtos tensoativos geralmente constituídos de sais de resinas de madeira, materiais protéicos e ácidos graxos e alguns detergentes sintéticos.

O ar incorporado por força do aditivo tem forma de pequenas bolhas de dimensões entre 10 e 1000 mícrons, distanciam-se entre si de 100 a 200 mícrons e possuem comportamento elástico, conforme Bauer [7].

O aditivo incorporado à mistura promove a redução da tensão superficial da água. Ainda segundo Bauer [7], ele atua envolvendo as bolhas de ar presentes e age também envolvendo as partículas de agregado miúdo mais finas e de cimento. $O$ conjunto formado entre as partículas sólidas envolvidas e as bolhas de ar, também envolvidas, apresenta maior estabilidade que os grupos isoladamente.

Apesar de reduzir a resistência mecânica do concreto, a incorporação de ar melhora a trabalhabilidade do mesmo, melhora também o comportamento do material durante o transporte, que é feito com menor possibilidade de segregação e diminui a exsudação.

\section{Desenvolvimento}

Neste projeto, foi desenvolvida uma abordagem adaptada do método de dosagem EPUSP/IPT, considerando as particularidades do concreto e as necessidades do estudo em questão. Uma vez que o objetivo recaía sobre a análise de concretos 
com incorporação de ar de forma comparativa, se pretendeu apoiar-se considerando 3 relações cimento/agregados, uma mais rica, uma intermediária e uma mais pobre. Em adição a isso, o estudo considerou as três relações cimento/agregado para 4 massas específicas distintas. Assim, foram considerados um grupo mais pobre, Grupo A (1:5), um intermediário, Grupo B (1:4) e um grupo mais rico, Grupo C (1:3) em relação à proporção de cimento da dosagem.

Para cada relação cimento/agregados, produziu-se 4 (quatro) concretos com massas específicas distintas, divididas em subgrupos (enumerados de 1 a 4 ), sendo dois subgrupos da classe normal (C; Subgrupos 1 e 2 ) e dois subgrupos da Classe leve (CL; Grupos 3 e 4), segundo classificação da NBR 8953 [5] apresentada na Tabela 1. As massas específicas selecionadas para estudo foram $2300 \mathrm{Kg} / \mathrm{m}^{3}$ e $2000 \mathrm{Kg} / \mathrm{m}^{3}$ para a classe normal, e $1700 \mathrm{Kg} / \mathrm{m}^{3}$ e $1500 \mathrm{Kg} / \mathrm{m}^{3}$ para a classe leve.

Com relação aos grupos a Tabela 2 a seguir apresenta os grupos, a relação cimento/agregados e as massas específicas consideradas.

Tabela 2: Apresentação dos grupos e subgrupos do estudo.

\begin{tabular}{|c|c|c|}
\hline Grupo (1:m) & Subgrupo & $\begin{array}{c}\text { Massa específica } \\
\text { aproximada }\left(\mathbf{k g} / \mathbf{m}^{\mathbf{3}}\right)\end{array}$ \\
\hline \multirow{3}{*}{$\mathrm{A}(1: 5)$} & 1 & 2300 \\
\cline { 2 - 3 } & 2 & 2000 \\
\cline { 2 - 3 } & 3 & 1700 \\
\cline { 2 - 3 } & 4 & 1500 \\
\hline \multirow{3}{*}{$\mathrm{B}(1: 4)$} & 1 & 2300 \\
\cline { 2 - 3 } & 2 & 2000 \\
\cline { 2 - 3 } & 3 & 1700 \\
\cline { 2 - 3 } & 4 & 1500 \\
\hline \multirow{3}{*}{ C (1:3) } & 1 & 2300 \\
\cline { 2 - 3 } & 2 & 2000 \\
\cline { 2 - 3 } & 3 & 1700 \\
\cline { 2 - 3 } & 4 & 1500 \\
\hline
\end{tabular}

$\mathrm{Na}$ etapa de elaboração dos traços de concreto se fixou uma medida de consistência como parâmetro de ensaio do abatimento, estabelecido de $170 \mathrm{~mm}$ tendo sido verificado para cada dosagem de concreto rodada. Também foi fixado o teor de argamassa $(\alpha \%)$ para todas as dosagens.

Assim, as relações água/cimento de cada classe de concreto foram obtidas em função da medida do abatimento $(170 \mathrm{~mm})$ atingida para as relações cimentoagregado trabalhadas $(m=5, m=4, m=3)$. Os valores obtidos estão dispostos na tabela 3 a seguir. 
Tabela 3: Relações água/cimento para cada grupo, obtidas em função da consistência estabelecida pelo ensaio de abatimento.

\begin{tabular}{|c|c|c|c|}
\hline Grupo & $\begin{array}{c}\text { Cimento-agregado } \\
\text { (c:m) }\end{array}$ & $\begin{array}{c}\text { Classe Consistência - } \\
\text { Abatimento (mm) }\end{array}$ & $\begin{array}{c}\text { Relação água- } \\
\text { cimento (a/c) }\end{array}$ \\
\hline A & $1: 5$ & $S 160-170$ & 0,63 \\
\hline B & $1: 4$ & $S 160-170$ & 0,50 \\
\hline C & $1: 3$ & $S 160-170$ & 0,43 \\
\hline
\end{tabular}

Para os ensaios referidos foram moldadas 108 corpos de prova de concreto.

$\mathrm{Na}$ dosagem dos concretos do estudo foram utilizados dois tipos de aditivo, um polifuncional e um incorporador de ar. Para a dosagem dos concretos com massa específica de aproximadamente $2300 \mathrm{Kg} / \mathrm{m}^{3}$ foi utilizado apenas 0 aditivo polifuncional. Para os demais concretos com incorporação de ar (com massas específicas aproximadas de $2000,1700,1500 \mathrm{Kg} / \mathrm{m}^{3}$ ), foram utilizados o aditivo polifuncional e o aditivo incorporador de ar, fornecido para o estudo.

\subsection{Produção do concreto em laboratório}

Após o trabalho de produção, a massa específica fresca dos concreto foi medida até se chegar ao valor aproximado daquelas pretendidas e estipuladas inicialmente.

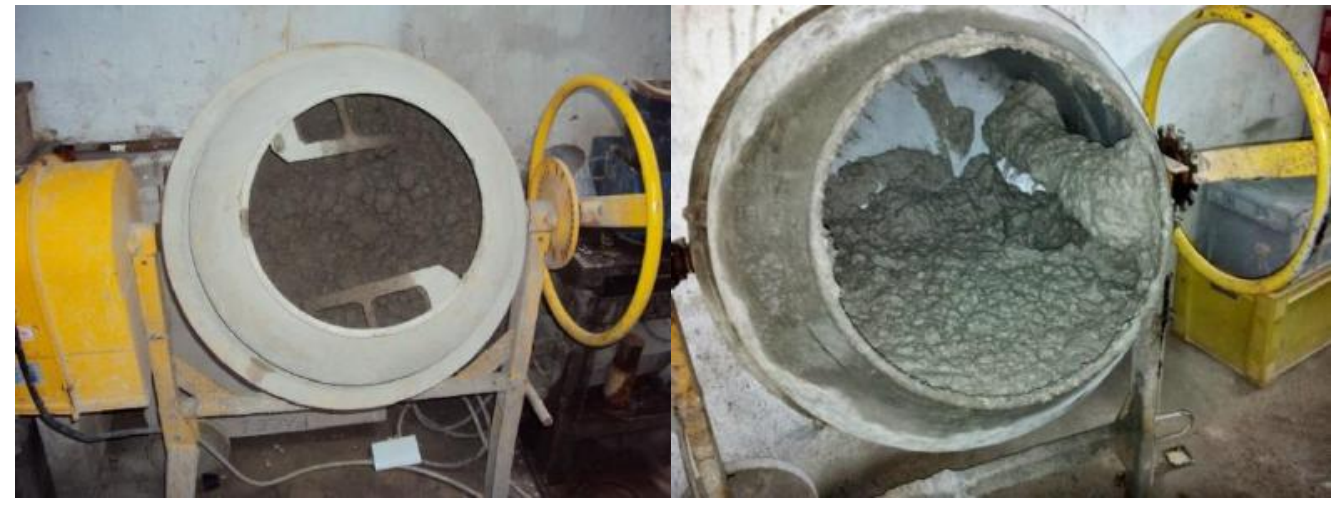

Figura 1: Mistura dos materiais em betoneira. Sem aditivo incorporador (esquerda) e com aditivo incorporador (direita).

\section{Resultados}

Nas idades previstas de 7 e 28 dias após a moldagem e cura, as amostras foram encaminhadas para ensaios de resistência à compresão axial. A figura 2 apresenta gráfico com as massas específicas obtidas nos concretos frescos para os diferentes grupos de estudo avaliados (Grupos A, B e C). 
MARIZ, J. C.; MONTEIRO, E. C. B.;COSTA E SILVA, A. J., AVALIAÇÃO COMPARATIVA DO COMPORTAMENTO MECÂNICO DE CONCRETOS LEVES COM AR INCORPORADO. $2^{\circ}$ Simpósio Paranaense de Patologia das Construções (2० SPPC), artigo 2SPPC1033, pp. 392-405, 2017. DOI: 10.4322/2SPPC.2017.033

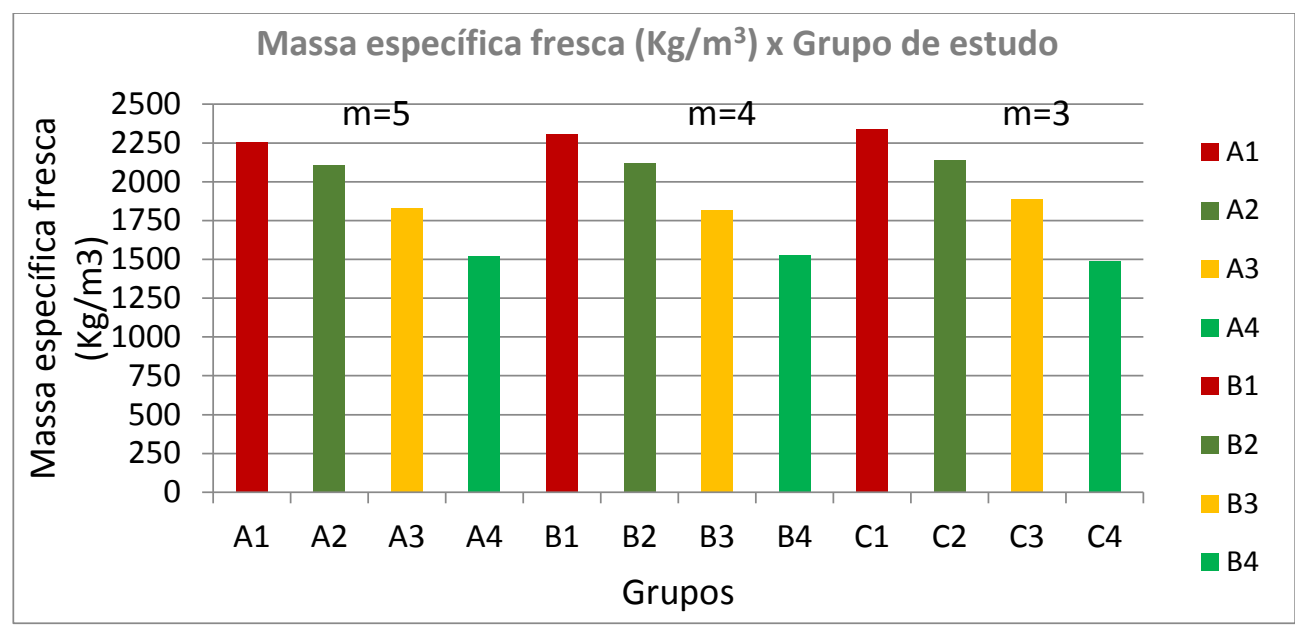

Figura 2: Gráfico massa específica x grupos do estudo

A figura 3 apresenta gráfico com os teores de ar incorporado obtidos no concreto fresco para os diferentes grupos de estudo avaliados.

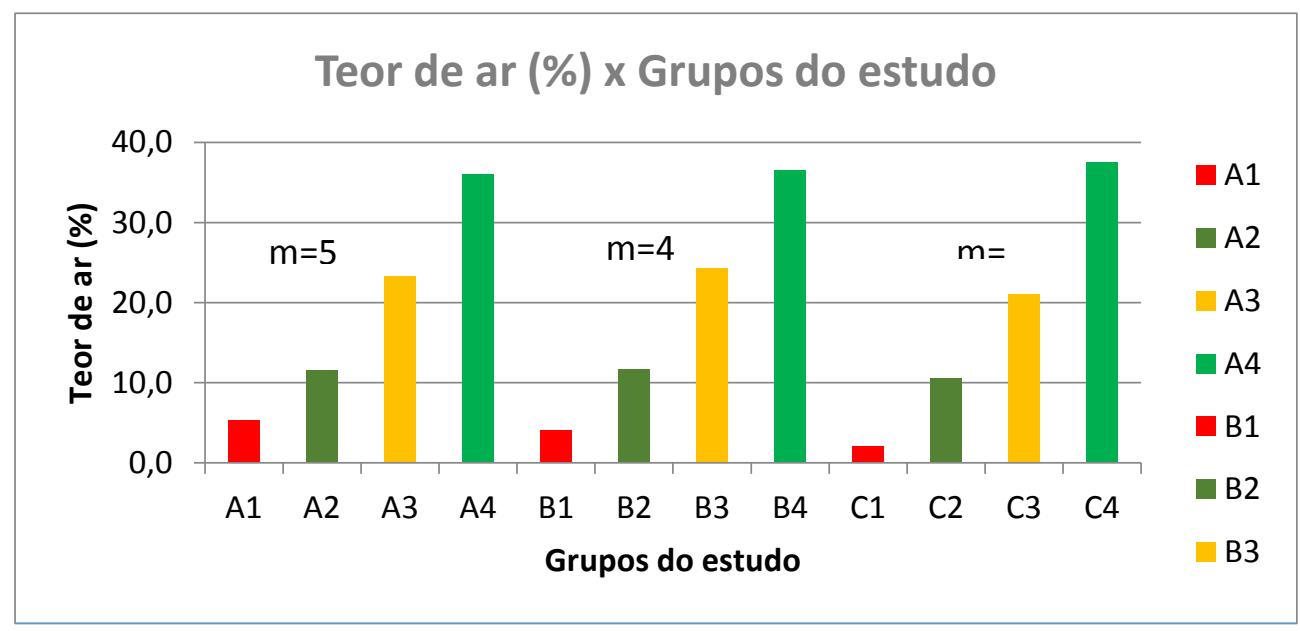

Figura 3: Gráfico do teor de ar x grupos do estudo

\subsection{Resultados de resistência à compressão e consumos de cimento.}

Foram realizados ensaios de resistência à compressão axial para todas as dosagens elaboradas e os resultados são apresentados na tabela a seguir. Os ensaios foram realizados para as idades de 7 e 28 dias. 
MARIZ, J. C.; MONTEIRO, E. C. B.;COSTA E SILVA, A. J., AVALIAÇÃO COMPARATIVA DO COMPORTAMENTO MECÂNICO DE CONCRETOS LEVES COM AR INCORPORADO. $2^{\circ}$ Simpósio Paranaense de Patologia das Construções (20 SPPC), artigo 2SPPC1033, pp. 392-405, 2017. DOI: 10.4322/2SPPC.2017.033

Tabela 4: Resultados dos ensaios de resistência média à compressão

\begin{tabular}{|c|c|c|c|}
\hline \multirow{3}{*}{ Grupo } & Massa específica do & \multicolumn{2}{|c|}{ Resistência à compressão (MPa) } \\
\cline { 2 - 4 } & estudo $\left(\mathbf{K g} / \mathbf{m}^{\mathbf{3}}\right)$ & $\mathbf{7}$ dias & $\mathbf{2 8}$ dias \\
\hline \multirow{3}{*}{$\mathrm{A}(1: 5)$} & 2300 & 32,6 & 40,8 \\
\cline { 2 - 4 } & 2000 & 18,4 & 23,3 \\
\cline { 2 - 4 } & 1700 & 7,7 & 9,8 \\
\cline { 2 - 4 } & 1500 & 1,8 & 2,1 \\
\hline \multirow{3}{*}{$\mathrm{B}(1: 4)$} & 2300 & 43,2 & 54,6 \\
\cline { 2 - 4 } & 2000 & 20,7 & 29,2 \\
\cline { 2 - 4 } & 1700 & 7,6 & 11,0 \\
\hline \multirow{3}{*}{$\mathrm{C}(1: 3)$} & 1500 & 1,1 & 1,8 \\
\cline { 2 - 4 } & 2300 & 50,0 & 65,4 \\
\cline { 2 - 4 } & 2000 & 22,1 & 28,7 \\
\cline { 2 - 4 } & 1700 & 14,7 & 18,0 \\
\hline
\end{tabular}

A partir dos dados obtidos e apresentados de resistências à compressão e das relações água-cimento para os concretos considerados no presente estudo, foram gerados os gráficos para análise da influência da relação água/cimento e da resistência à compressão para cada grupo de massa específica avaliada. A correlação existente entre a relação água/cimento e a resistência, fator determinante no estudo dos concretos e constatado pelo modelo de Abrams, é nitidamente observada para os concretos da classe convencional (massas específicas de $2300 \mathrm{Kg} / \mathrm{m}^{3}$ e $2000 \mathrm{Kg} / \mathrm{m}^{3}$ ). Já para os concretos da classe leve, contemplados no estudo (massas específicas de $1700 \mathrm{Kg} / \mathrm{m}^{3}$ e $1500 \mathrm{Kg} / \mathrm{m}^{3}$ ), a relação a/c por sí só não é o único parâmetro determinante do comportamento relativo à resistência. Uma vez que se adicionou o aditivo incorporador de ar à mistura, se verificou visualmente uma melhora na coesão dos materiais, sem que houvesse, no entanto, variações nos valores dos abatimentos dos concretos com massas específicas de 2300, 2000 e $1700 \mathrm{Kg} / \mathrm{m}^{3}$. Já os concretos com massas específicas de $1500 \mathrm{Kg} / \mathrm{m}^{3}$ apresentaram pequenos aumentos nos valores dos abatimentos, variando entre $190 \mathrm{~mm}$ e $210 \mathrm{~mm}$.

De forma geral, os consumos de cimentos dos concretos com menores massas específicas se mostram inferiores aos de maiores massas, como era esperado. Além disso, para um valor de "m" maior, estava associado consumos de cimento menores. Segue apresentado a seguir, gráfico com as curvas obtidas para cada massa específica dos consumos de cimento calculados. 
MARIZ, J. C.; MONTEIRO, E. C. B.;COSTA E SILVA, A. J., AVALIAÇÃO COMPARATIVA DO COMPORTAMENTO MECÂNICO DE CONCRETOS LEVES COM AR INCORPORADO. $2^{\circ}$ Simpósio Paranaense de Patologia das Construções ( $2^{\circ}$ SPPC), artigo 2SPPC1033, pp. 392-405, 2017. DOI: 10.4322/2SPPC.2017.033

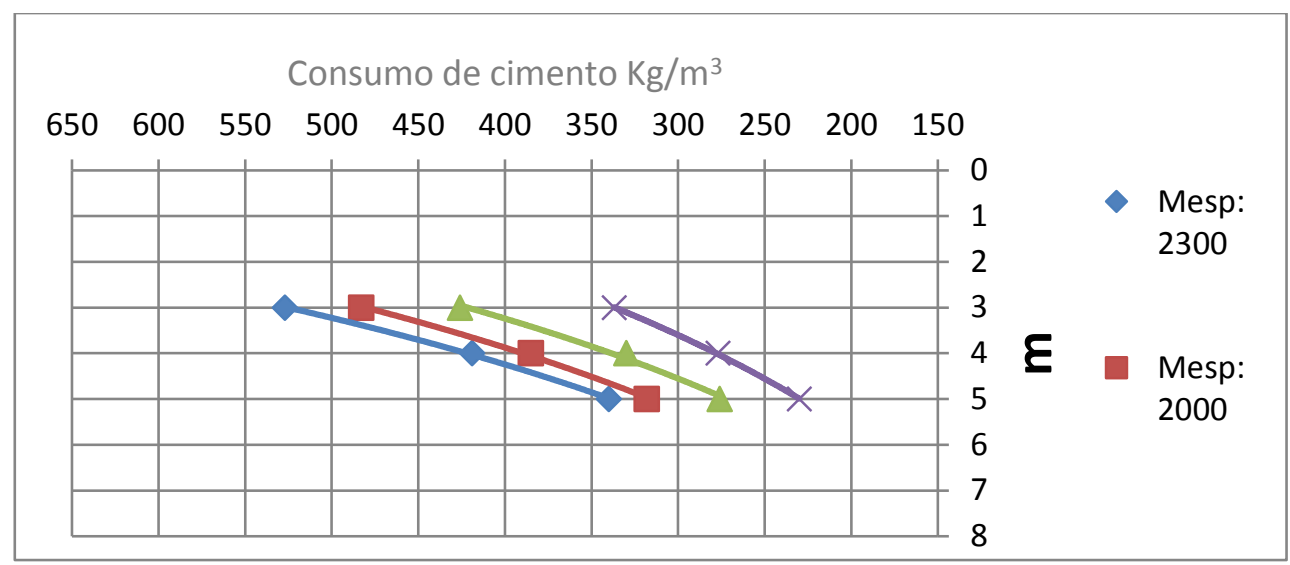

Figura 4: Consumo de cimento para as massas específicas contempladas

\subsection{Absorção, índice de vazios e massa específica seca}

Foram realizados ensaios para avaliação dos valores de absorção, índice de vazios e massas específicas secas dos concretos do estudo, para cada dosagem rodada. As massas específicas secas, obtidas através do ensaio do concreto endurecido, apresentaram variações em relação aos valores iniciais, e àqueles estipulados para as faixas de massa específica do estudo. Isso se deve às diferentes perdas de água a que os concretos estão submetidos uma vez no processo de endurecimento.

Os valores obtidos nos ensaios de índices de vazios permitiram observar que concretos com massas específicas menores apresentaram índice de vazios maiores em sua estrutura, além de com isso, apresentaram valores maiores de absorção de água. Para visualização destas características, segue gráfico relacionando as 3 propriedades.

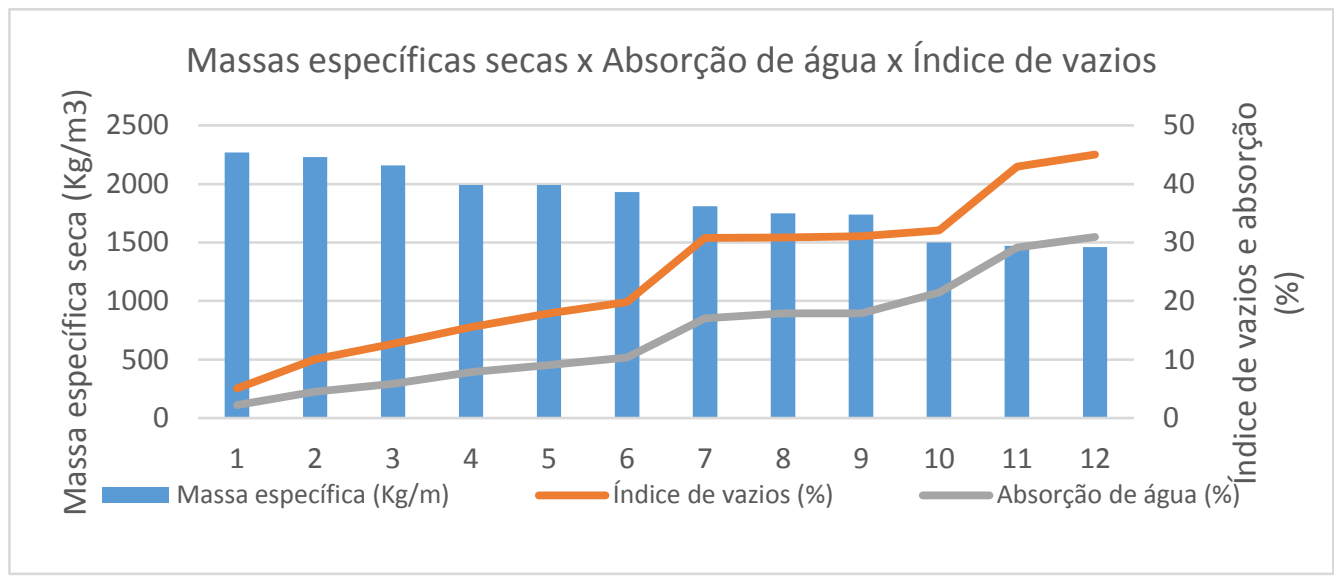

Figura 5: Relações entre massas especificas, índice de vazios e absorção de água

A figura 6 apresenta relação entre a massa específica e o índice de vazios para as amostras. 


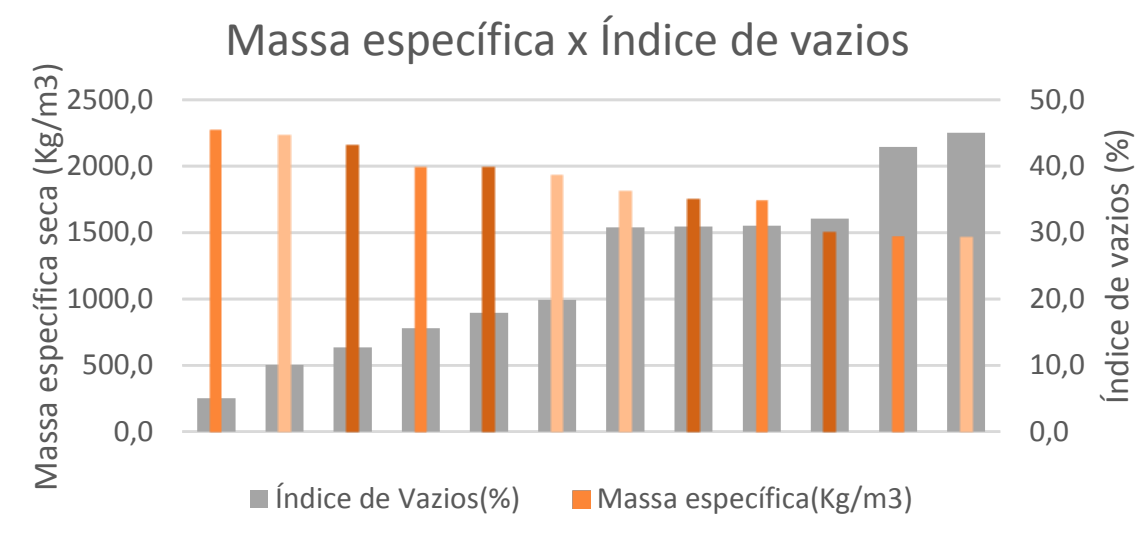

Figura 6: Relações entre massas especificas, índice de vazios

\subsection{Absorção capilar}

Foi ainda objeto do estudo avaliar as taxas de absorções capilares dos concretos dosados, tendo como objetivo verificar as propriedades envolvidas e seu reflexo evidenciado na capilaridade. Para tanto, foram ensaiados os concretos das 12 dosagens presentes no estudo. No caso específico da absorção capilar, a relação de maior influência observada estava associada ainda, à massa específica do concreto (obtida através da incorporação de ar) mas, além disso a relação água/cimento mostrou-se muito mais influente que nos ensaios de absorção, índice de vazios e massa específica seca.

Segue figura 7 com gráfico obtido das 3 propriedades consideradas, massa específica e absorção capilar para as 12 dosagens classificadas em ordem decrescente de massas específicas.

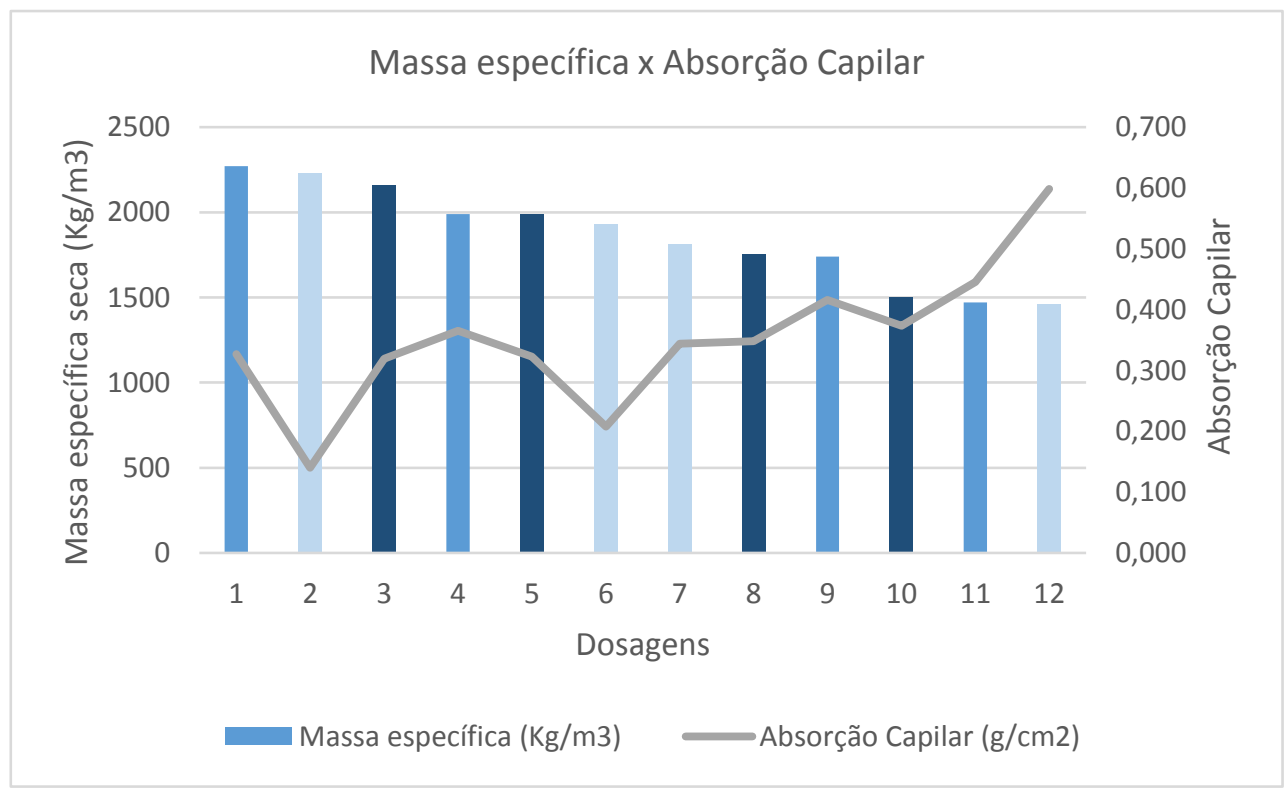

Figura 7: Relações entre massas específicas, absorção capilar

Observa-se ainda que, para os concretos sem o uso de aditivo incorporador, a absorção capilar acompanhou muito bem a variação na relação água/cimento. Para 
MARIZ, J. C.; MONTEIRO, E. C. B.;COSTA E SILVA, A. J., AVALIAÇÃO COMPARATIVA DO COMPORTAMENTO MECÂNICO DE CONCRETOS LEVES COM AR INCORPORADO. $2^{\circ}$ Simpósio Paranaense de Patologia das Construções ( ${ }^{\circ}$ SPPC), artigo 2SPPC1033, pp. 392-405, 2017. DOI: 10.4322/2SPPC.2017.033

os demais concretos, houve variações nos resultados. Mesmo assim, é possível visualizar através de interpretação gráfica uma tendência da curva de absorção em crescer a medida em que os valores de massas específicas diminuem.

\subsection{Massa específica e resistência à compressão}

Avaliando a relação existente entre as massas específicas dos concretos no estado seco e os valores de resistência à compressão obtidos foram realizados os gráficos que se seguem evidenciando que as propriedades possuem forte correlação.

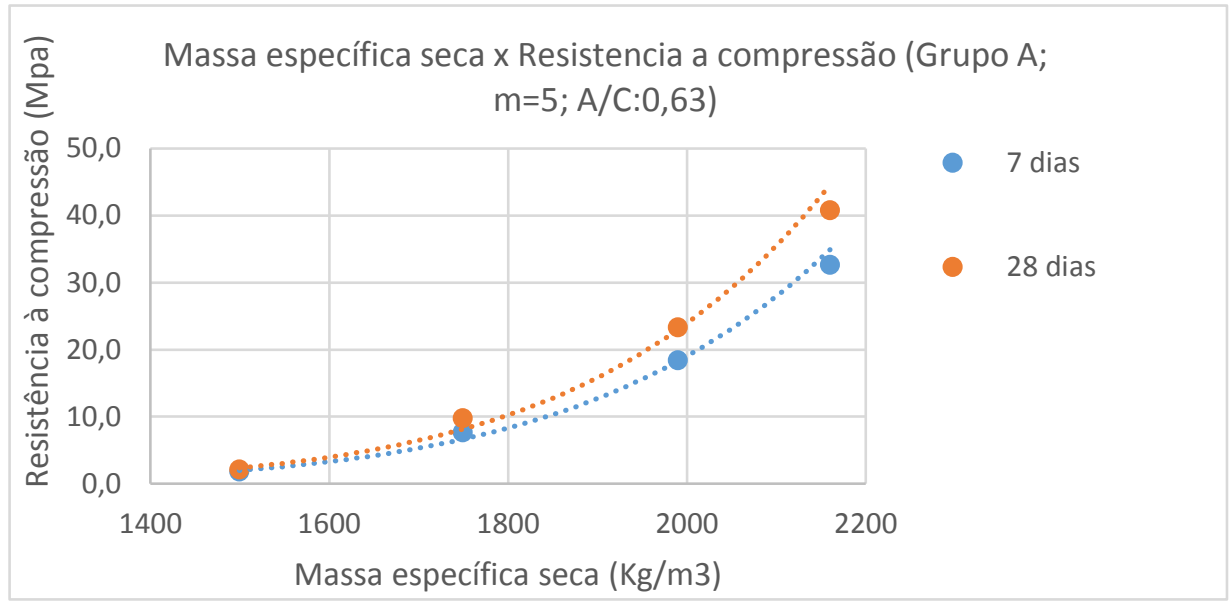

Figura 8: Resistencia a compressao e massas especificas - $\mathrm{m}=5$

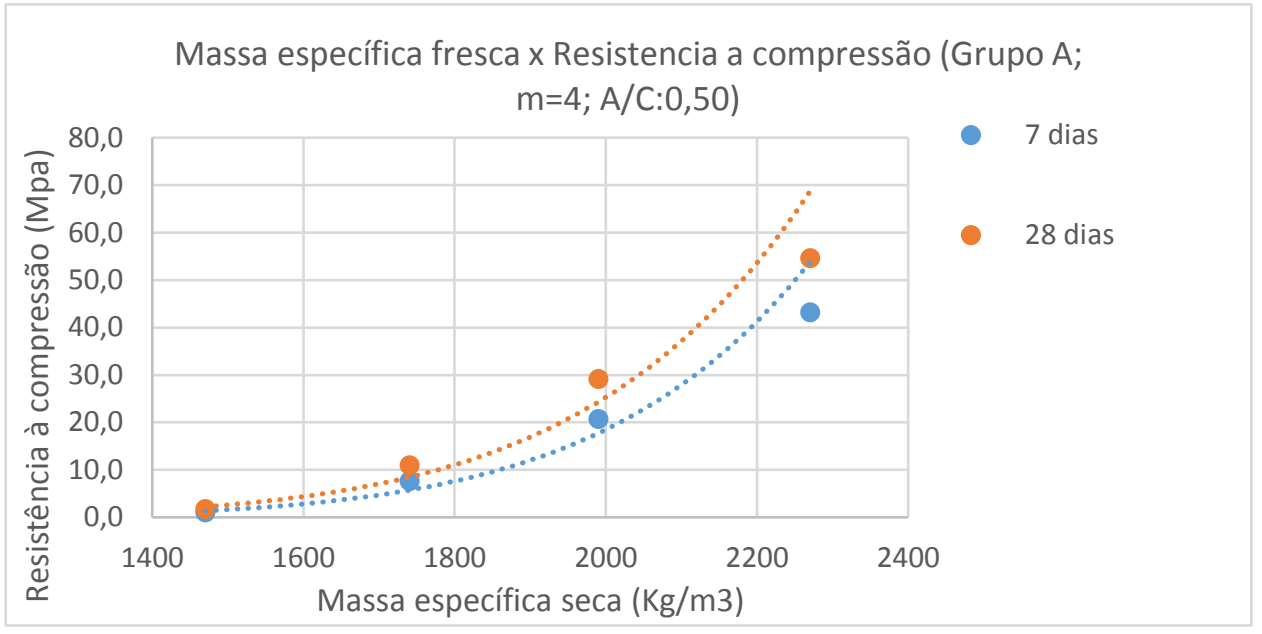

Figura 9: Resistencia a compressao e massas especificas $-\mathrm{m}=4$ 


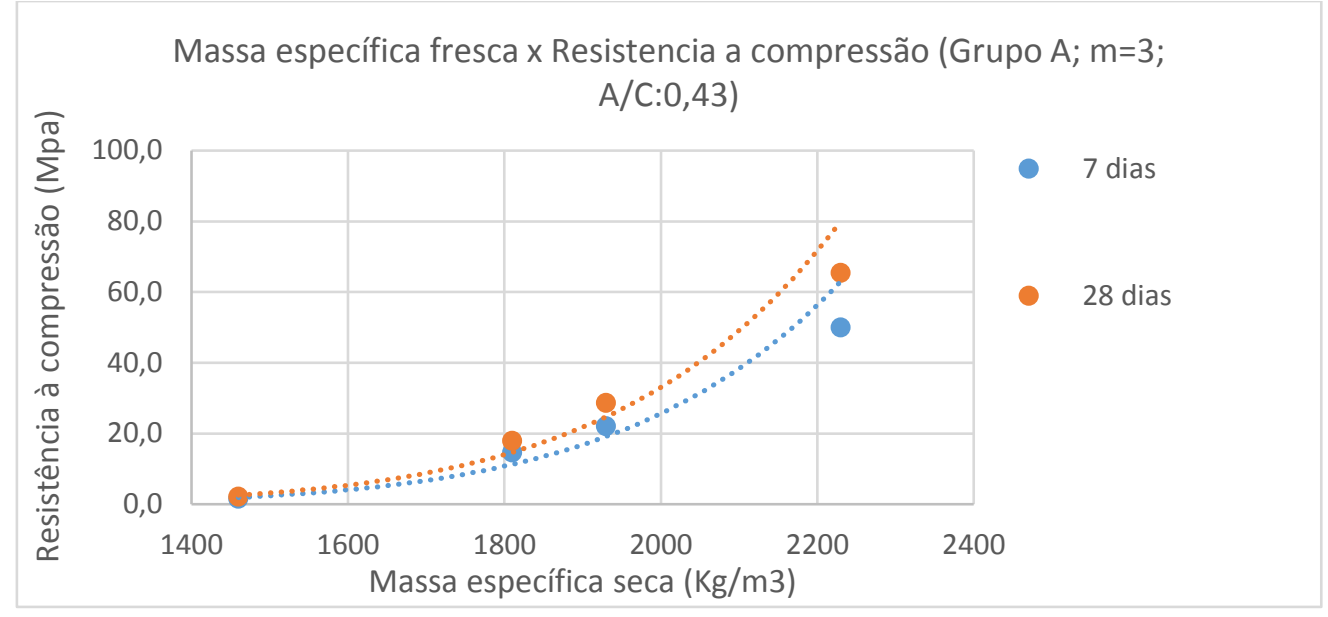

Figura 10: Resistencia à compressao e massas especificas - $m=3$

Os resultados refletem os valores de resistência à compressão maiores para aqueles concretos com valores de densidade maiores. Pode-se observar que com o aumento dos vazios nos concretos, acarretando em menores massas específicas, ocorre também a redução das suas resistências mecânicas. Pela NBR 12646 (1992), valores de resistência à compressão para lotes de concretos celulares devem atender ao mínimo de 2,5MPa.

\section{Conclusões}

Verificou-se que para um mesmo concreto, o aumento da incorporação de ar promovia uma redução na massa específica e consequente redução nas resistências mecânicas dos mesmos.

Esta variação teve um comportamento influenciado principalmente por duas propriedades: o aumento dos vazios nos concretos (dado o uso do incorporador) e a relação água/cimento utilizada.

Constatou-se no estudo que, os concretos com massas específicas próximas de $1500 \mathrm{Kg} / \mathrm{m}^{3}$, ou seja, aqueles com maior incorporação de ar, tinham seu comportamento praticamente orientado, do ponto de vista das resistências mecânicas, pela quantidade de vazios em seu interior, ficando em um segundo plano a relação água/cimento adotada. Os resultados apresentados, corroboram com os resultados obtidos por Teixeira Filho [8], em seu desenvolvimento experimental, onde um dos resultados observados foi a distinção da influência da relação água/cimento quando observadas diferentes classes de massa específicas.

Para os concretos estudados por Teixeira Filho com massas específicas de 1100 $\mathrm{Kg} / \mathrm{m}^{3}$ e $1300 \mathrm{Kg} / \mathrm{m}^{3}$, o aumento da relação água/cimento de 0,5 para 0,6 apresentou como resultado um aumento na resistência dos mesmos. Já para a classe de concretos com massa específica de $1700 \mathrm{Kg} / \mathrm{m}^{3}$ e $1900 \mathrm{Kg} / \mathrm{m}^{3}$, o mesmo aumento na relação água/cimento, de 0,5 para 0,6 , apresentou como resultado valores menores de resistência à compressão. 
Em nosso estudo isso é observado para as dosagens com massas específicas de $1500 \mathrm{Kg} / \mathrm{m}^{3}$, onde para uma relação água/cimento de 0,63 a resistência à compressão axial é superior a uma dosagem com relação água/cimento de 0,50.

Para os resultados obtidos, se pode considerar que as mudanças na influência das relações a/c, em massa, na resistência à compressão axial se justificam pela redução de suas massas específicas e aumento dos vazios dos concretos Teixeira Filho [8].

Além disso observamos em nosso estudo que, concretos com massa específica da ordem de $1900 \mathrm{Kg} / \mathrm{m}^{3}$, possuem propriedades mecânicas interessantes com valores de resistência à compressão na faixa dos $20 \mathrm{MPa}$, aliadas aos benefícios possíveis da incorporação de ar, tais quais consumos reduzidos.

Em se tratando dos fenômenos de capilaridade, os concretos avaliados apresentaram aumento na absorção capilar com a diminuição das suas massas específicas.

É sabido que a permeabilidade dos concretos é um fator crucial para a durabilidade dos mesmos. Quanto mais permeável os concretos, mais suscetíveis às ações deletérias de agentes agressivos presentes no ambiente. Assim, atenção especial deve ser dada quando do uso de concretos que apresentam índices de vazios elevados e alta capilaridade, como o caso presente no estudo.

\subsection{Profundidade de carbonatação}

Com o intuito de avaliar os concretos estudados do ponto de vista do fenômeno de carbonatação, foram separados corpos de prova, remanescentes dos ensaios de absorção total, para serem utilizados na avaliação. Uma vez que o ensaio anterior não era destrutivo, se pôde avaliar estes concretos submetidos à ação atmosférica do ambiente do laboratório, onde permaneceram por períodos de 11 meses de exposição.

Para a realização do ensaio, tomou-se como base as recomendações e o procedimento descrito no RILEM TC056-CPC-18. As amostras foram seccionadas à seco, a 1/3 de uma das suas faces (topo ou base). Após a secção, os corpos de prova foram aspergidos com uma solução de fenolftaleína para identificação da zona de transição do $\mathrm{pH}$. A zona de transição onde ocorre o avanço da frente de carbonatação, por possuir pH abaixo de 9 tende a ficar incolor na presença da solução, a zona com pH superior a 9, tende a ficar com coloração violeta.

Assim, é possível identificar o avanço da frente de carbonatação conforme apresentado nas figuras a seguir. 


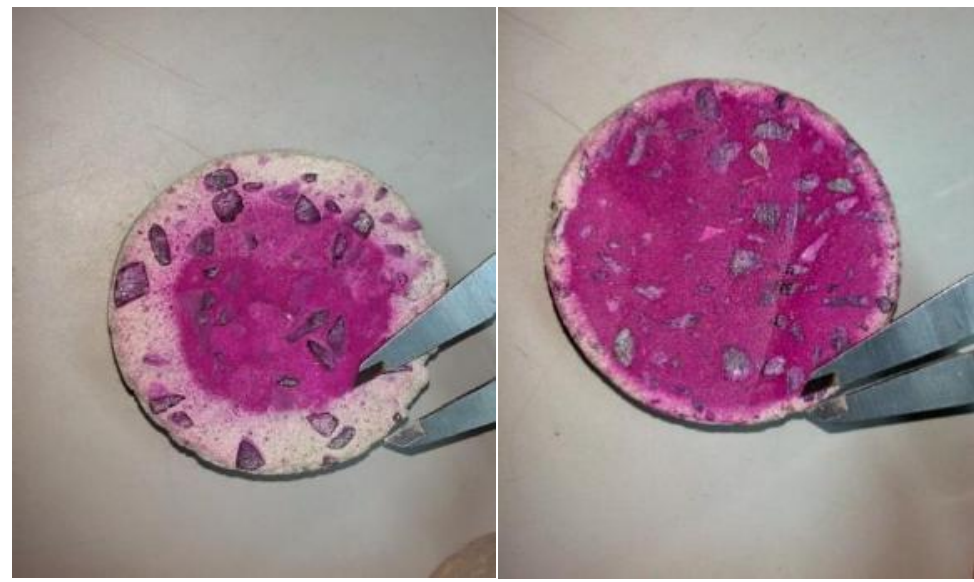

Figura 11: Medição da profundidade de carbonatação

Tabela 5: Valores medidos de profundidade de carbonatação e previsão do avanço baseado no RILEM

\begin{tabular}{|c|c|c|c|c|c|c|c|c|c|}
\hline \multirow[t]{2}{*}{ Grupo } & \multirow[t]{2}{*}{$A / C$} & \multirow[t]{2}{*}{$1: m$} & \multirow[t]{2}{*}{ Subgrupo } & \multirow{2}{*}{$\begin{array}{c}\text { Massa } \\
\text { específica } \\
\left(\mathrm{kg} / \mathrm{m}^{3}\right)\end{array}$} & \multirow{2}{*}{$\begin{array}{c}\text { Profundidade } \\
\text { de } \\
\text { carbonatação } \\
\text { após } 11 \\
\text { meses }(\mathrm{mm})\end{array}$} & \multicolumn{4}{|c|}{$\begin{array}{c}\text { Previsão do avanço da } \\
\text { frente de carbonatação em } \\
\text { anos }\end{array}$} \\
\hline & & & & & & $20 \mathrm{~mm}$ & $30 \mathrm{~mm}$ & $40 \mathrm{~mm}$ & $50 \mathrm{~mm}$ \\
\hline \multirow{4}{*}{ A } & \multirow{4}{*}{0,63} & \multirow{4}{*}{$1: 5$} & 1 & 2300 & 2,29 & 70 & 157 & 280 & 437 \\
\hline & & & 2 & 2000 & 5,85 & 11 & 24 & 43 & 67 \\
\hline & & & 3 & 1700 & 9,52 & 4 & 9 & 16 & 25 \\
\hline & & & 4 & 1500 & - & - & - & - & - \\
\hline \multirow{4}{*}{ B } & \multirow{4}{*}{0,5} & \multirow{4}{*}{$1: 4$} & 1 & 2300 & 1,75 & 120 & 269 & 479 & 748 \\
\hline & & & 2 & 2000 & 4,86 & 16 & 35 & 62 & 97 \\
\hline & & & 3 & 1700 & 8,20 & 5 & 12 & 22 & 34 \\
\hline & & & 4 & 1500 & - & - & - & - & - \\
\hline \multirow{4}{*}{ C } & \multirow{4}{*}{0,43} & \multirow{4}{*}{$1: 3$} & 1 & 2300 & 0 & - & - & - & - \\
\hline & & & 2 & 2000 & 4,21 & 21 & 47 & 83 & 129 \\
\hline & & & 3 & 1700 & 4,87 & 15 & 35 & 62 & 97 \\
\hline & & & 4 & 1500 & - & - & - & - & - \\
\hline
\end{tabular}

Em nossa avaliação, sob o ponto de vista da profundidade de carbonatação, verificamos que os concretos leves possuem avanço da frente de carbonatação muito superior aos concretos convencionais. Mesmo aqueles concretos com uma relação água/cimento reduzida, no caso dos do grupo $\mathrm{C}(\mathrm{a} / \mathrm{c}: 0,43)$, apresentaram, para as massas específicas menores (2000 e $1700 \mathrm{~kg} / \mathrm{m} 3$ ) profundidades de carbonatação significativas para os 11 meses de idade do ensaio. Não foi possível determinar a taxa de avanço das frentes de carbonatação para os concretos do grupo de massas específicas na faixa dos $1500 \mathrm{~kg} / \mathrm{m}^{3}$ nem daqueles relativos a massa específica na faixa dos $2300 \mathrm{~kg} / \mathrm{m}^{3}$ para a relação a/c 0,43 . Os primeiros por terem apresentado em toda a superfície seccionada o avanço total da frente de carbonatação e os últimos por não ter sido possível determinar avanço algum. 
Estes resultados levantam a importância de se avaliar a permeabilidade relativa a estes concretos e à tomada de ações no que diz respeito às medidas de proteção das superfícies de forma a tratá-las com intuito de diminuir a permeabilidade destes concretos e assim mitigar a ação de agentes externos caso venham a ser utilizados em regiões com influência de agentes agressivos presentes na atmosfera.

\section{Referências}

[1] Helene, Paulo.; Andrade, Tibério. Concreto de Cimento Portland. In: Isaia,Geraldo Cechella. Materiais de Construção Civil e Princípios de Ciência e Engenharia de Materiais. São Paulo: IBRACON, 2007. V2, Cap. 27, p. 905 944.

[2] Corsini, Rodnei. Paredes normatizadas. Norma inédita para paredes de concreto moldadas in loco entra em vigor e promete impulsionar uso da tecnologia em edificações In: Revista Téchne, No. 183. Dezembro de 2011. Disponível em: <http://techne.pini.com.br/engenharia-civil/183/paredesnormatizadas-norma-inedita-para-paredes-de-concreto-moldadas-287955-

1.aspx>

[3] NBR 16055 (2012). Parede de concreto moldada no local para a construção de edificações - Requisitos e procedimentos. Associação Brasileira de Normas Técnicas - ABNT, Rio de Janeiro, Brasil.

[4] Rossignolo, João Adriano. Concreto Leve Estrutural. Produção, Propriedades Microestrutura e Aplicações. São Paulo: Editora Pini, 2009.

[5] NBR 8953 (2015). Concreto para fins estruturais - Classificação pela massa específica, por grupos de resistência e consistência. Associação Brasileira de Normas Técnicas - ABNT, Rio de Janeiro, Brasil.

[6] Mehta, P.K.; Monteiro, P.J. Concreto: microestrutura, propriedades e materiais. 3a ed. IBRACON, 2008. p. 674.

[7] Bauer, Luiz Alfredo Falcão. Materiais de Construção: 5.ed. Rio de Janeiro: ABDR Afiliada, 1994. v.1.f

[8] Teixeira Filho, F. J.; Tezuka, Y. Considerações Sobre Algumas propriedades dos Concretos Celulares Espumosos. Boletim Técnico da Escola Politécnica da USP. Departamento de Engenharia da Construção Civil. São Paulo. EPUSP, 1992. 